\title{
Betaine Hydrochloride
}

National Cancer Institute

\section{Source}

National Cancer Institute. Betaine Hydrochloride. NCI Thesaurus. Code C82301.

The hydrochloride form of betaine, a crystalline alkaloid occurring in sugar beets and other plants. Betaine, acting as a transmethylating metabolic intermediate, is the oxidation product of choline. Betaine hydrochloride is used as a gastric acidifier supplement. 